\title{
Experimental Research on the Impact of Engine oils on Vehicle Fuel Economy
}

\author{
Mo Yimin ${ }^{1, \text { a }}$, Wang Jun ${ }^{2, b^{*}}$, Wang Junping ${ }^{3, c}$, Zhou Wenjun $^{4, d}$ \& Dong Tuo,e \\ Wuhan University of Technology, Wuhan, Hubei Province, China, 430070 \\ amoyimin@whut.edu.cn \\ b*wj430507@163.com \\ c wangjpzm@163.com \\ d332920622@qq.com \\ e whut_dt@163.com
}

Keywords: engine oils; NEDC cycle; vehicle fuel economy; test accuracy; low viscosity.

Abstract. As the problem of vehicle fuel consumption and environmental pollution has caused wide public concern over the recent years, improving vehicle fuel economy is extremely urgent. Through vehicle fuel consumption test on mini cars based on New European Driving Cycle (NEDC), the impact of energy-conserving engine lubricants on improving vehicle fuel economy was researched in this paper, the problem of test accuracy has been detailedly studied as well.

\section{Introduction}

Along with the sustained rapid development of China's economy, the production and ownership of car has rapidly and continually increased. According to incomplete statistics, the number of car ownership in China could reach $1.2 \times 10^{9} \sim 1.5 \times 10^{9}$ as of 2020 and $2.3 \times 10^{9} \sim 2.5 \times 10^{9}$ as of 2030 (Ma 2007). The energy dilemma and environmental pollution caused by vehicle fuel consumption and emissions have brought great pressure to our country. With the people's growing awareness of environmental crisis and the gradually increased fuel economy standards, improving vehicle fuel economy has become one of the main issues for automobile manufacturer.

\section{The Vehicle Fuel Economy and NEDC Cycle}

According to the studies of a large number of scholars, fuel economy is determined by various factors like vehicle weight, engine, drive train and wind resistance coefficient and so on, among these factors, the engine fuel consumption is the most central part of vehicle fuel consumption (Kong 2007, Richard \& Edward 2005). To improve the fuel consumption of the engine, using the low-viscosity energy-saving engine oil, reducing engine friction loss and improving power have become one of the effective ways to improve engine fuel economy (Zhang et al. 2013).

By the principle of the engine, the engine power $P_{i}$ and mechanical efficiency $\eta_{m}$ are as follows:

$$
P_{i}=P_{e}+P_{m}
$$

$$
\begin{aligned}
& \eta_{m}=\frac{P_{e}}{P_{i}}=1-\frac{P_{m}}{P_{i}} \\
& \eta_{m}=\frac{W_{e}}{W_{i}}=1-\frac{W_{m}}{W_{i}} \\
& \eta_{m}=1-\frac{P_{m m}}{P_{m i}}
\end{aligned}
$$


where $P_{e}=$ effective power of an engine; $P_{m}=$ mechanical loss of engine power; $W_{e}=$ effective work of the engine; $W_{i}=$ engine's indicated work; $W_{m}=$ mechanical loss of engine work; $P_{m m}=$ average mechanical loss pressure of cylinder; $P_{m i}=$ average indicated pressure of cylinder.

According to [1] [4], if the value of $P_{e}, W_{m}$, or $P_{m m}$ decreases through the optimization of engine oils, the mechanical efficiency could be improved.

Studies on engine fuel economy have been researched in domestic and foreign for many years, Engine oil saving bench has developed from procedure ASTM to program VID (Wei et al. 2005), however, the vehicle fuel consumption levels are usually measured by NEDC cycle many years, which is used a chassis dynamometer provided under the national standard "light vehicle emission limits and measurement methods" (GB18352.3-2005). This paper researched domestic mini-car fuel economy under the NEDC cycle by using several deployed energy-saving engine oil, analyzed and improved some problems in the test to verify the impact of engine oil on vehicle fuel economy.

\section{Test Equipment and Candidate Oil}

\section{Test equipment}

The place of the test in this paper is in the mini car manufacturer's emissions-laboratory, according to the national standard, the laboratory mainly includes AVL 48 "compact chassis-dynamometer, AVL five components emission analyzer (4000 light Digas), WEISS environment-warehouse and HORIB emission analyzer. This paper only introduce the related parameters and system of AVL 48 "compact chassis dynamometer, see table 1.

\section{Candidate oil}

There are two main ways for engine oil to reduce engine friction. On the one hand, the friction loss under hydrodynamic lubrication, such as the lubrication of bearing, can be reduced with low viscosity engine oil (Kusoke et al. 2012). On the other hand, effective friction modifier can form a protective film on the metal with both physical and chemical reaction to reduce the friction coefficient in the region of the boundary lubrication and mixed lubrication, Such as cylinder liner piston group lubrication and valve-train lubrication (Brent et al. 2011, Li et al. 2007). Six kinds of engine oils were developed to test the fuel economy of the vehicle aiming the two aspects mentioned above. The details of the oils were specified in table 2.

Table 1 The related parameters and system composition in AVL 48" compact chassis dynamometer

\begin{tabular}{lll}
\hline & AVL $48^{\prime \prime}$ Compact Chassis-Dynamometer \\
\hline \multirow{3}{*}{ Parameters } & Diameter [mm] & 1219.2 \\
& Mass Range[kg] & $450-5400$ \\
& Axle Load[kg] & 4500 \\
& Maximum Speed[km/h] & 200 \\
\hline \multirow{3}{*}{ System } & 48"Chassis-Dynamometer & \\
composition & Device Used For Vehicle Center Of Symmetry \\
& Cooling Fan \\
\hline
\end{tabular}

Table 2 Physical and chemical index and the related information of the test sample

\begin{tabular}{lcccccc}
\hline Type & Reference & \multicolumn{5}{c}{ Candidate } \\
\hline Vis-grade & $5 \mathrm{~W} 30$ & $5 \mathrm{~W} 20$ & 0W20 & $5 \mathrm{~W} 20$ (1) & 5 W20 (2) & 5W20 (3) \\
Credential & API SM & API SN & API SN & DEXOS1 & DEXOS1 & DEXOS1 SN \\
KV40,[cSt] & 64.70 & 49.41 & 46.77 & 48.67 & 48.98 & 45.33 \\
KV100,[cSt] & 10.95 & 8.570 & 5.75 & 8.210 & 8.610 & 8.802 \\
VI & 135 & 151 & 150 & 142 & 141 & 178 \\
HTHS $\left(150^{\circ} \mathrm{C}\right), \mathrm{c}$ & 3.12 & 2.71 & 2.57 & 2.69 & 2.72 & 2.80 \\
P.S. & \multicolumn{7}{c}{ Basic Formulation } & & H.P*; FM & H.P; FM+VII \\
\hline
\end{tabular}




\section{Analysis of Test Accuracy}

Effect of engine oil on the vehicle's fuel economy is a very complex issue, which has a great relationship with the vehicle design, use conditions, driving habits, lubricating oil composition and fuel oil composition (Riaz \& Martin 2005, Rupesh et al. 2011). On this basis, the accuracy of the test equipment also affect the accuracy of the final test results, coupling of various factors may result in greater volatility of test results. In this paper, 11 times on Reference oil API Specification SM-5W30 for NEDC driving cycle fuel consumption measurement test were carried out, Test records and results shown in Table 3 and Figure 1.

Table 3 The initial data of the reference oil API specificationSM-5W30

\begin{tabular}{ccccccc}
\hline NO. & Driver & Vol[V] & $\begin{array}{c}\text { Temp } \\
\text { engine }\left[{ }^{\circ} \mathrm{C}\right]\end{array}$ & $\begin{array}{c}\text { Temp } \\
\text { gearbox }\left[{ }^{\circ} \mathrm{C}\right]\end{array}$ & $\begin{array}{c}\text { Temp } \\
\text { axle }\left[{ }^{\circ} \mathrm{C}\right]\end{array}$ & $\begin{array}{c}\text { Sub } \\
\text { time[h] }\end{array}$ \\
\hline 1 & $\mathrm{~A}$ & 12.43 & 26.10 & 25.42 & 25.15 & 15.5 \\
2 & $\mathrm{~B}$ & 12.12 & 24.50 & 24.35 & 24.20 & 7.5 \\
3 & $\mathrm{~A}$ & 12.25 & 25.00 & 24.80 & 24.80 & 13.5 \\
4 & $\mathrm{~B}$ & 12.36 & 26.10 & 25.50 & 24.95 & 7.5 \\
5 & $\mathrm{~A}$ & 12.3 & 25.55 & 25.05 & 24.91 & 14 \\
6 & $\mathrm{~A}$ & 12.45 & 24.70 & 24.80 & 24.20 & 15.5 \\
7 & $\mathrm{~B}$ & 12.45 & 25.20 & 25.10 & 25.00 & 10 \\
8 & $\mathrm{C}$ & 12.78 & 28.20 & 26.30 & 23.80 & 7.5 \\
9 & $\mathrm{~B}$ & 12.51 & 24.59 & 24.22 & 24.20 & 13.5 \\
10 & $\mathrm{C}$ & 12.5 & 26.45 & 25.67 & 25.33 & 8 \\
11 & $\mathrm{~B}$ & 12.41 & 25.58 & 25.31 & 25.02 & 13 \\
\hline
\end{tabular}

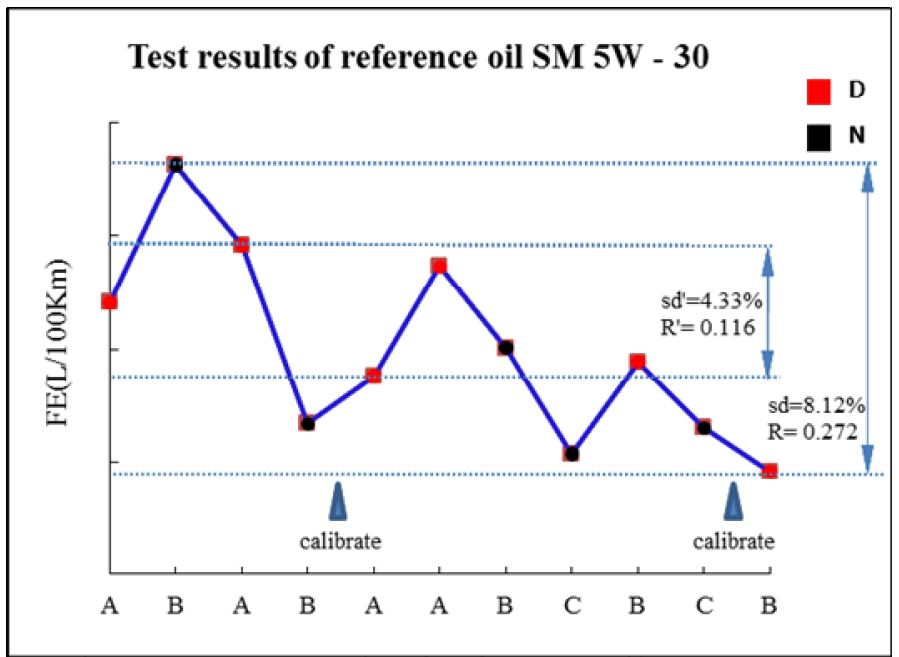

Figure 1 Test result of reference oil SM $5 \mathrm{~W}-30$

It can be seen in Figure 1 that the results of 11 experiments for Reference oil NEDC driving cycle fuel consumption measurement test show that fluctuations in $\mathrm{R}$ reached $0.272 \mathrm{~L} / 100 \mathrm{Km}$ and the standard deviation sd reached 8.12 percent. Even if the test results were further screened, the effective test results fluctuate $\mathrm{R}$ has reached $0.116 \mathrm{~L} / 100 \mathrm{Km}$, the standard deviation sd reach $4.33 \%$. The test precision has caused serious influence the reliability of the test results. Therefore, I assume that the impact of uncontrollable factors coupling effect on the test results is constant and in-depth analysis of various uncontrollable factors, control measures, Finally, Controllable factors are divided into the following test.

Tire

The driving distance of the test car is 45,000 kilometers, and no tires are changed before testing, sliding friction occurs during the test since the tire tends to be soft. And the tire condition is influenced by the moving of the test car between the garage and laboratory back and forth. Harder 
tire is chose to prevent the sliding friction with a certain running-in period, and the test car should not be pulled out of the test chamber before the end of the oil test.

\section{Voltage}

The vehicle state records during the test show that initial voltage fluctuated widely, which is not normal phenomenon and caused by the battery aging after investigation. According to the follow-up test analysis, $0.3 \mathrm{~V}$ initial voltage difference leads to $0.1 \mathrm{~L} / 100 \mathrm{Km}$ fuel consumption difference of micro-car vehicle. A series of control measures were taken, including replacing with new batteries, turning off all electronic devices, and charging the battery during test gap, to keep the voltage consistent.

\section{Temperature}

Combing vehicle initial temperature and test results to analyze, it was found that initial temperature of the vehicle greatly affected the test results with a liner relation. While recording data showed that even if the soaking time had reached the required standard, the initial temperature of the vehicle may not reach test requirements because of the ambient temperature. So the soaking time should be adjusted timely according to the change of ambient temperature to keep the initial temperature of vehicle control in a small range, preventing too high or too low.

\section{Driver}

The number of drivers is too much when driving. Qualifications of working conditions and operation habits are widely different for various drivers. Also, mental conditions of a driver can lead to experimental variations. So choose only one skillful driver as far as possible, and decrease result deviations which may result from driver change.

\section{Experiment standardization}

This thing that facility standardizations may cause much unidirectional variations can be found in experiment results. This can be caused by many experiment tasks per day. Experiment sources are tense. As a result, stability of the facility conditions can't be guaranteed. So do the experiment standardization before conducting an experiment every time and make sure experiment conditions stable.

\section{Fuel changing procedure}

Due to strong activity of surface additives of energy saving-engine lubricant, the part surfaces can be absorbed firmly. That means carrying effect. Measures that do washes frequently when adopting the next experiment fuel to keep engine temperature $80 \sim 90{ }^{\circ} \mathrm{C}$ are taken. Specific procedures are showed in picture 2 .

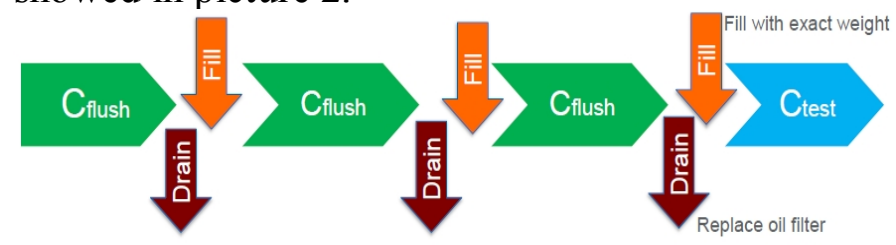

\section{Test number}

Figure 2 Fuel changing and washing procedure

Although the controllable factors have been effectively controlled, the coupling effect of uncontrollable factors still should be considered. So every oil needs to be tested for many times until getting 3-4 effective test results.

Data analysis

Due to the various influence factors of the vehicle fuel economy, reference oil test results vary with the test plan. In order to ensure the reliability test results, more reference oil tests will still be in need. Analysis procedure of test oil results are shown in Figure 3. 

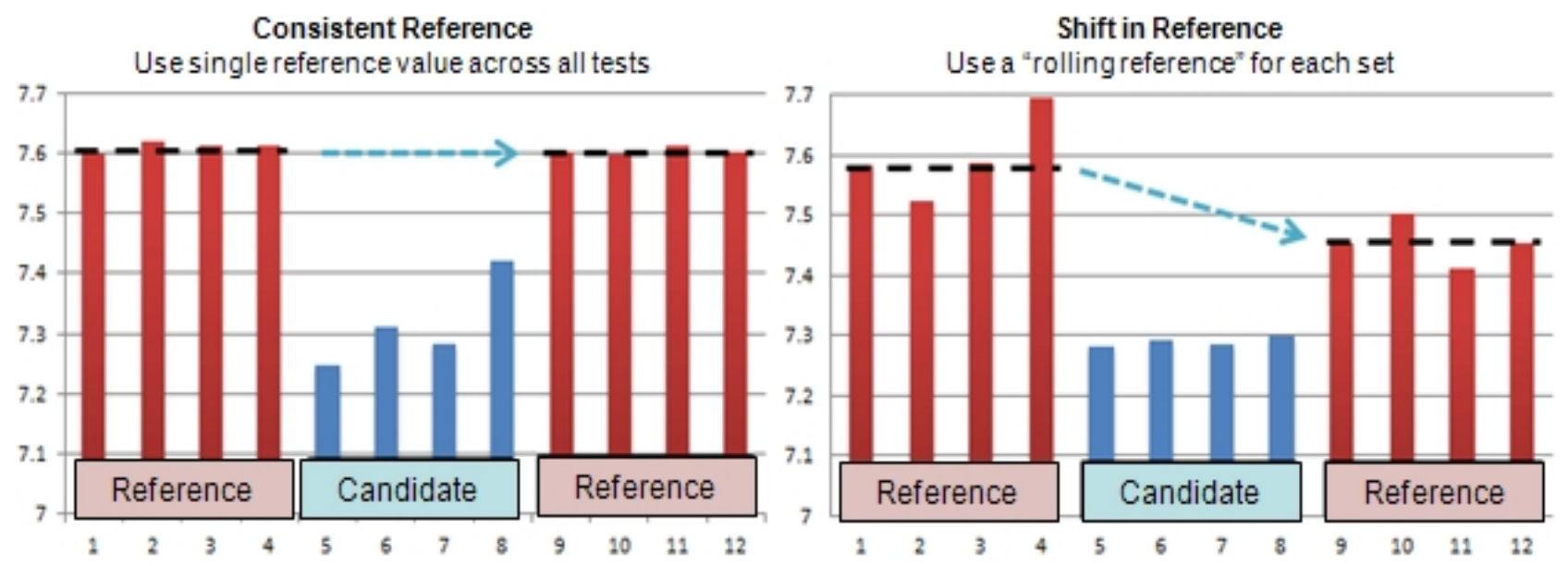

Figure 3 Analysis procedure of test oil results

\section{Analysis of Experiment Result}

Under the condition of the above-mentioned controllable factors had been controlled strictly. Then take the reference oil SM - 5W30 (API specification) for 8 times NEDC driving cycles of fuel consumption measurement, it can be found that the testing precision has improved a lot. The specific testing records and the results will be shown in table 4 and figure 4

Table 4 The initial data of the reference oil SM-5W30which has been improved its precision

\begin{tabular}{ccccccc}
\hline NO. & Driver & Vol[V] & $\begin{array}{c}\text { Temp } \\
\text { engine }\left[{ }^{\circ} \mathrm{C}\right]\end{array}$ & $\begin{array}{c}\text { Temp } \\
\text { gearbox }\left[{ }^{\circ} \mathrm{C}\right]\end{array}$ & $\begin{array}{c}\text { Temp } \\
\text { axle }\left[{ }^{\circ} \mathrm{C}\right]\end{array}$ & $\begin{array}{c}\text { Sub } \\
\text { time[h] }\end{array}$ \\
\hline 1 & $\mathrm{~B}$ & 12.21 & 25.15 & 25.10 & 25.10 & 19 \\
2 & $\mathrm{~B}$ & 12.21 & 25.29 & 25.10 & 24.80 & 17 \\
3 & $\mathrm{C}$ & 12.24 & 25.27 & 25.25 & 25.10 & 10 \\
4 & $\mathrm{~B}$ & 12.2 & 25.40 & 25.50 & 25.39 & 14 \\
5 & $\mathrm{C}$ & 12.23 & 25.20 & 25.22 & 25.15 & 11 \\
6 & $\mathrm{~B}$ & 12.2 & 25.21 & 25.20 & 25.19 & 16 \\
7 & $\mathrm{~B}$ & 12.24 & 25.32 & 25.24 & 25.12 & 15 \\
8 & $\mathrm{~B}$ & 12.21 & 25.00 & 24.95 & 24.88 & 17.5 \\
\hline
\end{tabular}

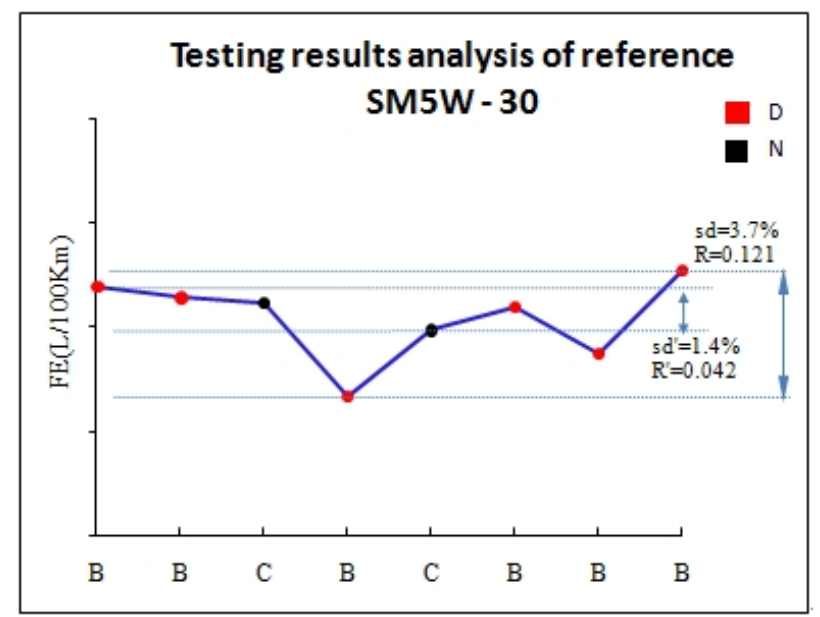

Figure 4 The analysis of testing result on reference oil SM5W-30 which has improved its precision

As figure 4 shows, after screening eight NEDC fuel consumption testing results of the reference oil, the fluctuation of the Effective testing results which is called " $R$ ", its value is just 0.042 $\mathrm{L} / 100 \mathrm{Km}$, and SD is $1.4 \%$. There is a certain reliability which is provided by the experimental precision. As can be learned from Figure 4, although the value of " $R$ " has been decreased 
significantly, the fluctuation of "R" still remains $0.121 \mathrm{~L} / 100 \mathrm{Km}$. So the uncontrollable factors of vehicle fuel economy testing still have huge impacts on testing results.

Under the condition of this testing accuracy, 5 testing oil have been performed NEDC fuel consumption testing. The analysis on all kinds of testing oil is based on above-mentioned statistical methods. The situation of how the testing samples improve vehicle fuel economy is shown in figure 5.

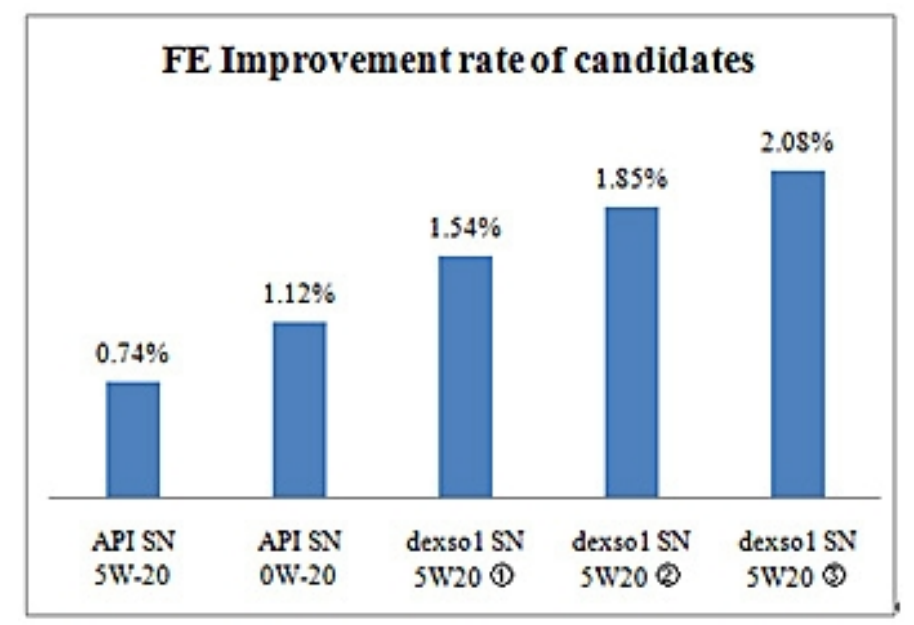

Figure 5 The increasing rate of vehicle fuel economy for all kinds of testing oil

The analysis of test results: under the API specification, when the engine lubrication oil improved every level of viscosity, the vehicle fuel economy will also rise. But it doesn't mean that blindly low viscosity will improve vehicle fuel economy, the 5W201) of DEXOS1 specifications is more than $0.42 \% 0 \mathrm{~W} 20$ of the API specifications on the promotion rate of the vehicle fuel economy, and choosing the 5W20(2) with high-performance friction is more than $0.31 \%$ the $5 \mathrm{~W} 20$ (1) with basic formula on the promotion rate of the vehicle fuel economy, the promotion of the vehicle fuel economy will further enhance when add the high-performance viscosity on the basis of 5W202.

\section{Conclusion}

The influence of the engine lubrication oil on the vehicle fuel economy is a multi-factor coupling problem. By using the NEDC cycle to prove this problem has a large accuracy error. In order to improve the test accuracy, strictly controlling the controllable factors can be feasible.

By comparing with API and DEXOS1 engine oil test results, low viscosity and special additives play an important role in improving vehicle fuel economy. High specification, low viscosity and the high performance special additives of engine oil formulation technology has further potential for fuel economy improvement.

\section{References}

[1] Brent Dohner et al. 2011. Development of novel friction modifier technology. $S A E$ 2011-01-2126

[2] Kong Chunhua. 2007. Research on fuel economy analysis of the used passenger car. Changchun: Jilin university

[3] Kosuke Fujimoto et al. 2012. Development of ILSAC GF-5 0W-20 fuel economy gasoline engine oil. SAE 2012-01-1614

[4] Li Guiyun et al. 2007. Study of effect of friction modifiers on fuel efficiency. Lubrication Engineering 32(4): 140-144

[5] Ma Yanli \& Gao Yuee. 2007. Forecast of automobile population in China. Journal of Highway and Transportation Research and Development 24(1): 121-125

[6] Riaz A.M. \& Martin P. 2005. Experimental and theoretical evaluation of simultaneous piston assembly, valve train and engine bearing friction in a fired engine. WTC2005-64255

[7] Richard A.R. \& Edward K.N. 2005. On-road testing and characterization of fuel economy of light-duty vehicles. Michigan: SAE World Congress 
[8] Rupesh Roshan et al. 2011. A boundary lubrication friction model sensitive to detailed engine oil formulation in an automotive cam/follower interface. Jounal of Tribology: 040201

[9] Wei Wenyu et al. 2005. On the development of engine saving bench test and the influence factors of oil fuel economy. Lubricating Oil 20(6):1-7

[10] Zhang Ziqin et al. 2013. On fuel sensitivity of engine key conditions based on the NEDC cycle. Shanghai Auto:19-24 